OPEN ACCESS

Edited by:

Qiang Wang,

Institute of Hydrobiology, Chinese

Academy of Sciences, China

Reviewed by:

Ping Xu,

Shanghai Jiao Tong University, China

Autar Krishen Mattoo,

Agricultural Research Service,

United States Department

of Agriculture, United States

*Correspondence:

Jing Han

hanjing@im.ac.cn

Hua Xiang

xiangh@im.ac.cn

Specialty section:

This article was submitted to Microbiotechnology, Ecotoxicology

and Bioremediation,

a section of the journal

Frontiers in Microbiology

Received: 26 June 2018 Accepted: 12 November 2018

Published: 29 November 2018

Citation:

Zuo Z-Q, Xue Q, Zhou J,

Zhao D-H, Han J and Xiang H (2018) Engineering Haloferax mediterranei as an Efficient Platform for High Level

Production of Lycopene.

Front. Microbiol. 9:2893.

doi: 10.3389/fmicb.2018.02893

\section{Engineering Haloferax mediterranei as an Efficient Platform for High Level Production of Lycopene}

\author{
Zhen-Qiang Zuo ${ }^{1,2}$, Qiong Xue ${ }^{1,2}$, Jian Zhou' ${ }^{1}$, Da-He Zhao', Jing Han ${ }^{1,2 *}$ and \\ Hua Xiang ${ }^{1,2 *}$ \\ ' State Key Laboratory of Microbial Resources, Institute of Microbiology, Chinese Academy of Sciences, Beijing, China, \\ ${ }^{2}$ College of Life Sciences, University of Chinese Academy of Sciences, Beijing, China
}

Lycopene attracts increasing interests in the pharmaceutical, food, and cosmetic industries due to its anti-oxidative and anti-cancer properties. Compared with other lycopene production methods, such as chemical synthesis or direct extraction from plants, the biosynthesis approach using microbes is more economical and sustainable. In this work, we engineered Haloferax mediterranei, a halophilic archaeon, as a new lycopene producer. H. mediterranei has the de novo synthetic pathway for lycopene but cannot accumulate this compound. To address this issue, we reinforced the lycopene synthesis pathway, blocked its flux to other carotenoids and disrupted its competitive pathways. The reaction from geranylgeranyl-PP to phytoene catalyzed by phytoene synthase (CrtB) was identified as the rate-limiting step in $\mathrm{H}$. mediterranei. Insertion of a strong promoter $\mathrm{P}_{\text {phaR }}$ immediately upstream of the crtB gene, or overexpression of the heterologous $\mathrm{CrtB}$ and phytoene desaturase (Crtl) led to a higher yield of lycopene. In addition, blocking bacterioruberin biosynthesis increased the purity and yield of lycopene. Knock-out of the key genes, responsible for poly(3-hydroxybutyrateco-3-hydroxyvalerate) (PHBV) biosynthesis, diverted more carbon flux into lycopene synthesis, and thus further enhanced lycopene production. The metabolic engineered $H$. mediterranei strain produced lycopene at $119.25 \pm 0.55 \mathrm{mg}$ per gram of dry cell weight in shake flask fermentation. The obtained yield was superior compared to the lycopene production observed in most of the engineered Escherichia coli or yeast even when they were cultivated in pilot scale bioreactors. Collectively, this work offers insights into the mechanism involved in carotenoid biosynthesis in haloarchaea and demonstrates the potential of using haloarchaea for the production of lycopene or other carotenoids.

Keywords: lycopene, biosynthesis, Haloferax mediterranei, rate-limiting steps, phytoene synthase, phytoene desaturase, bacterioruberin, PHBV

\section{INTRODUCTION}

Lycopene is a C40 isoprenoid compound in the carotenoid family. Due to its anti-oxidative and anti-cancer activities (Sies and Stahl, 1998; Gajowik and Dobrzynska, 2014), lycopene has been widely used for nutritional supplements, pharmaceutical and cosmetic products (Wei et al., 2017). The conventional methods for lycopene production include direct extraction from plants, 
chemical synthesis and microbial fermentation. Among these methods, microbial production of lycopene is more economical and sustainable (Chen et al., 2016). Recently, with the development of metabolic engineering techniques and synthetic biology, lycopene overproduction has been realized in Escherichia coli (Zhu et al., 2015; Wei et al., 2017; Wu et al., 2018; Xu et al., 2018), yeast (Xie et al., 2015a; Schwartz et al., 2017), Blakeslea trispora (Liu et al., 2012; Wang et al., 2016, 2017), and Rhodobacter sphaeroides ( $\mathrm{Su}$ et al., 2018). However, the field is seeking a better platform for large-scale production of lycopene or other carotenoids. Halophilic archaea (haloarchaea) belong to the domain Archaea and are unique microorganisms that survive under the high salt condition (Singh and Singh, 2017). Many haloarchaeal species are capable of producing the compounds of the carotenoid family (Rodrigo-Banos et al., 2015), such as phytoene, $\beta$-carotene, lycopene, as well as the derivatives of bacterioruberin and salinixanthin (de Lourdes Moreno et al., 2012). Particularly, they hold several advantages for carotenoid production: the high-salt tolerance enables haloarchaea cultivation under non-sterile condition and thus reduces the energy cost (Singh and Singh, 2017). Additionally, the process of carotenoid extraction from haloarchaea is relatively simple, as the cell lysis undergoes in low sodium chloride $(\mathrm{NaCl})$ condition. Consequently, haloarchaea are considered as an alternative producer for carotenoids (Naziri et al., 2014).

Haloferax mediterranei can use probably the largest range of single carbon sources and grows faster than other known members of the Halobacteriaceae (Oren and Hallsworth, 2014). Its complete genome information is available (Han et al., 2012), and the pyrF-based gene knockout system for genomewide manipulation has also been well-established in this strain (Liu et al., 2011). With these merits, H. mediterranei has been one of the most common model strains for the study of physiology and metabolism in archaea. For example, it has been used to investigate poly(3-hydroxybutyrate-co3-hydroxyvalerate) (PHBV) biosynthesis and its metabolism regulation processes (Han et al., 2013, 2017; Zhao et al., 2013; Bhattacharyya et al., 2014; Cai et al., 2015). However, only a few studies on its carotenoid production has been reported till recently. Fang et al. (2010) improved the C50 carotenoid production to $0.604 \mathrm{~A}_{494 \mathrm{~nm}} / \mathrm{mL}$ broth via a two-stage cultivation approach. Chen et al. (2015) used extruded rice bran and starch under optimal conductivity of brined medium for a high red pigment production of $556 \mathrm{mg} / \mathrm{L}$. However, there is no work investigating either the production of other carotenoids (e.g., lycopene), or the pathway engineering to improve carotenoid production in $H$. mediterranei.

In this study, we explored the possibility to use H. mediterranei as a potential cell factory for lycopene production by multiple strategies (Figure 1). First, we attempted to identify and eliminate the rate-limiting steps involved in lycopene biosynthesis. Then we disrupted bacterioruberin synthesis to increase lycopene accumulation and purity. Heterologous phytoene synthase (CrtB) and phytoene desaturase (CrtI) encoding genes from other haloarchaea were employed for further enhancing lycopene production. Subsequently, we blocked PHBV synthesis to divert more acetyl-CoA flux to lycopene synthesis and also complemented the pyrF gene in the engineered strain for its future application in industrial scale. We finally obtained a metabolic engineered $H$. mediterranei strain with relatively high purity and production of lycopene.

\section{MATERIALS AND METHODS}

\section{Strains, Medium, and Culture Conditions}

All the strains used in this study are listed in Supplementary Table S1. E. coli JM109 (Sambrook, 1989) was used for plasmids construction and E. coli JM110 was used to eliminate the methylated plasmid in vivo (Palmer and Marinus, 1994). Luria Broth (LB) medium was used for E. coli culture at $37^{\circ} \mathrm{C}$. When needed, $100 \mu \mathrm{g} / \mathrm{mL}$ of ampicillin was added to LB medium. $H$. mediterranei was cultivated at $37^{\circ} \mathrm{C}$ in nutrient-rich AS-168 medium (per liter, $5 \mathrm{~g}$ casamino acids, $5 \mathrm{~g}$ yeast extract, $1 \mathrm{~g}$ sodium glutamate, $3 \mathrm{~g}$ trisodium citrate, $2 \mathrm{~g} \mathrm{KCl,} 20 \mathrm{~g} \mathrm{MgSO}_{4}$. $7 \mathrm{H}_{2} \mathrm{O}, 200 \mathrm{~g} \mathrm{NaCl}, 5 \mathrm{mg} \mathrm{FeSO}{ }_{4} \cdot 7 \mathrm{H}_{2} \mathrm{O}$, and $0.036 \mathrm{mg} \mathrm{MnCl}_{2}$. $4 \mathrm{H}_{2} \mathrm{O}$ [pH 7.0]). AS-168SY medium was similar to AS-168 medium, except that yeast extract was excluded. Plasmids were transformed into $H$. mediterranei with the polyethylene glycolmediated transformation method (Cline et al., 1989). When required, AS-168 medium was supplemented with $50 \mathrm{mg} / \mathrm{mL}$ uracil (Sangon, China) and $250 \mathrm{mg} / \mathrm{mL}$ 5-Fluoroorotic acid (Sangon, China) for counter-selection of the recombinants without pyrF marker. For lycopene production, a 1\% (V/V) seed culture of $H$. mediterranei or its mutants was inoculated into a shake flask containing $50 \mathrm{~mL}$ of MG medium (per liter, $110 \mathrm{~g}$ $\mathrm{NaCl}, 20.51 \mathrm{~g} \mathrm{MgCl}_{2}, 29.52 \mathrm{~g} \mathrm{MgSO}_{4}, 5 \mathrm{~g} \mathrm{KCl}, 1 \mathrm{~g} \mathrm{CaCl}, 2 \mathrm{~g}$ $\mathrm{NH}_{4} \mathrm{Cl}, 0.0375 \mathrm{~g} \mathrm{KH}_{2} \mathrm{PO}_{4}, 10 \mathrm{~g}$ glucose, $15 \mathrm{~g}$ PIPES, Fe(III) citrate, and $1 \mathrm{~mL}$ trace element solution SL-6 [pH 7.2]) (Antón et al., 1988) and cultured at $37^{\circ} \mathrm{C}$ and $200 \mathrm{rpm}$ for 7 days.

\section{Plasmid Construction for Gene Overexpression}

The native candidate genes involved in lycopene synthesis were amplified with primers listed in Supplementary Table S2 from the $H$. mediterranei genomic DNA. The heterologous crt genes $H A H \_2563\left(\right.$ crtB $\left.B_{\mathrm{ha}}\right), H A H \_1058\left(\mathrm{crt} I_{\mathrm{ha}}\right)$ and $O E \_3093 R\left(\operatorname{crt} B_{\mathrm{hs}}\right)$, OE_3381R $\left(c r t I_{\mathrm{hs}}\right)$ were obtained via PCR from the genomic DNA of Haloarcula hispanica and Halobacterium salinarum, respectively. Amplified fragments were inserted into pWLR [derived from pWL502 by insertion of a strong promoter $\mathrm{P}_{\mathrm{phaR}}$ (Cai et al., 2012)] digested with BamHI and XbaI, by using One Step Cloning Kit (Yeasen, Co., Ltd., China), to generate plasmids for gene overexpression under the control of promoter $\mathrm{P}_{\mathrm{phaR}}$ (Supplementary Table S1).

\section{Plasmid Construction for Gene Integration in Chromosome}

All plasmids for gene knock-in or knock-out were constructed based on a suicide plasmid pHFX (Liu et al., 2011). A 583bp DNA fragment located immediately upstream of $c r t B_{\mathrm{hm}}$ was amplified with primer pair $\operatorname{crtB}$-in-1/crtB-in-2 from $H$. mediterranei genomic DNA. Another 580-bp fragment 
A

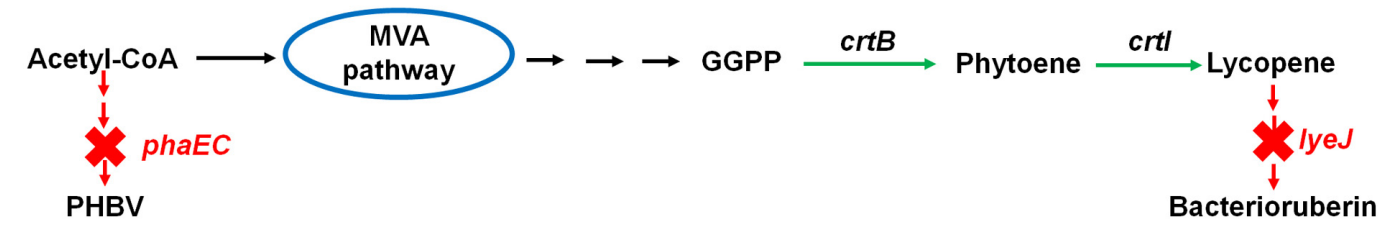

B

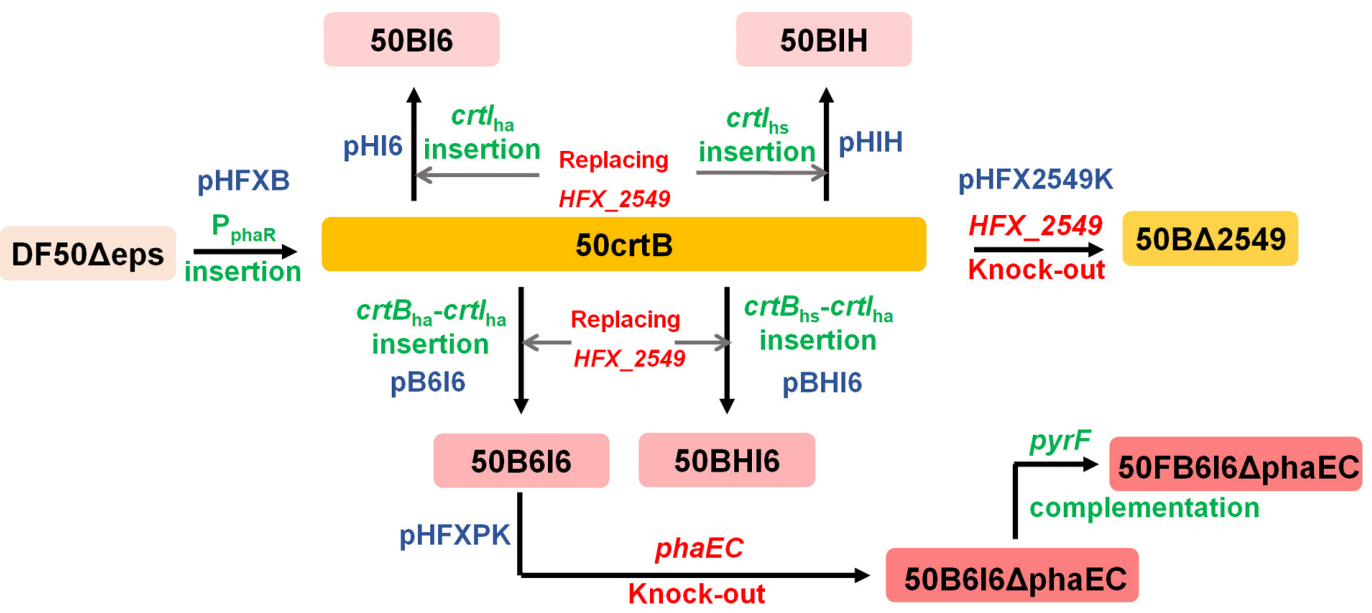

FIGURE 1 | Schematic illustration of engineered $H$. mediterranei for lycopene production. (A) Enhancement of lycopene synthesis by enhancing lycopene biosynthetic pathway and blocking its flux to bacterioruberin and its competitive pathway for PHBV biosynthesis. Green arrows represent enhanced steps and red arrows and crosses represent blocked steps. (B) Flowchart of engineering $H$. mediterranei strain for increasing lycopene synthesis. Green terms represent gene insertion and red ones represent gene deletion. The blue terms show the plasmids used for constructing the mutants of $H$. mediterranei.

containing promoter $\mathrm{P}_{\mathrm{phaR}}$ and the partial $5^{\prime}$ region of $\operatorname{crt} B$ was amplified with primer pair $c r t B$-in-3/crtB-in-4 from plasmid pW2547 used for $c r t B_{\mathrm{hm}}$ overexpression (Supplementary Table S1). Then, the two PCR products were inserted into the plasmid pHFX to construct the integration plasmid of pHFXB, which was used to replace the native promoter of HFX_2547 $\left(c r t B_{\mathrm{hm}}\right)$ in chromosome. For the heterologous crt gene integration, a 524-bp fragment up-stream of HFX_2549 and a 529-bp fragment down-stream of HFX_2549 were amplified by relevant primer pairs (Supplementary Table S2). Different crt gene fragments containing $\mathrm{P}_{\text {phaR }}$ were amplified by using $\operatorname{crt} B_{\text {ha }}$, $c r t I_{\mathrm{ha}}, c r t B_{\mathrm{hs}}$, and $c r t I_{\mathrm{hs}}$ overexpression plasmids pWHA2563, pWHA1058, pWOE3093, and pWOE3381 (Supplementary Table S1) as PCR template, respectively. The corresponding homologous arm fragments and different crt genes, containing promoter $\mathrm{P}_{\text {phaR }}$, were assembled into $\mathrm{pHFX}$ to construct plasmids containing different crt genes used for their integration in chromosome (Supplementary Figure S1 and Supplementary Table S1). Similar to the plasmid construction method as described above, primer pairs HFX_2549-K1/HFX_2549-K2 and HFX_2549-K3/HFX_2549-K4 were used to construct the plasmid pHFX2549K for HFX_2549 knock-out. Primer pairs phaEC$\mathrm{K} 1 /$ phaEC-K1 and phaEC-K3/phaEC-K4 were used for the construction of pHFXPK for phaEC knock-out (Supplementary Table S1).

\section{Analysis of Carotenoids by Thin Layer Chromatography (TLC)}

Carotenoids in acetone extract obtained from different cultures were analyzed by thin layer chromatography (TLC), following the protocol described by Strand et al. (1997) with slight modifications. Briefly, after cultivation in MG medium for 7 days, the cells $(1 \mathrm{~mL})$ were harvested by centrifugation $\left(12,000 \times g\right.$ for $5 \mathrm{~min}$, at $\left.4^{\circ} \mathrm{C}\right)$, and resuspended in acetone ( $1 \mathrm{~mL}$ ) under a reduced light condition to prevent photobleaching and degradation (Alper and Stephanopoulos, 2008). The acetone supernatant containing carotenoids was collected and transferred to a new tube. This process was repeated until the pellets were totally white. Acetone extracted carotenoids $(10 \mu \mathrm{L})$ were analyzed by TLC on a silica plate (GF254, Qingdao Haiyang Chemical, Co., Ltd., China) with acetone and n-heptane $(1: 1, v / v)$ as the development liquid in fume hood at room temperature. In addition, the visualized spot on the resulting TLC plate was scraped off, and extracted with $200 \mu \mathrm{L}$ of acetone. The obtained supernatant was then scanned under $350-550 \mathrm{~nm}$.

\section{Lycopene Quantification}

The lycopene content in the extract was determined by using a HPLC system (Agilent, 1260, United States) 
equipped with a ZORBAX Eclipse XDB-C18 column $(4.6 \mathrm{~mm} \times 150 \mathrm{~mm}, 5 \mu \mathrm{m})$ and a UV/VIS detector. The absorption was detected at $450 \mathrm{~nm}$. The mobile phase consisted of methanol-isopropanol $(65: 35 \mathrm{~V} / \mathrm{V})$ with a flow rate of $1 \mathrm{~mL} / \mathrm{min}$ at $30^{\circ} \mathrm{C}$. Injection volume of sample was $20 \mu \mathrm{L}$. The lycopene concentration was calculated based on the calibration curve of lycopene (Macklin Biochemical, Co., Ltd., China).

\section{PHA Content Analysis}

The cells were collected by centrifugation at $10,000 \times \mathrm{g}, 4^{\circ} \mathrm{C}$, $15 \mathrm{~min}$ and lyophilized. The lyophilized cells were treated with a mixture of chloroform and methanol containing 3\% (v/v) sulfuric acid at $95^{\circ} \mathrm{C}$ for $4 \mathrm{~h}$. The resulting hydroxyacyl methylesters were then analyzed by GC-6820 instrument (Agilent, United States) as described by Han et al. (2007).

\section{RNA Extraction and Quantitative Reverse Transcription-PCR (qRT-PCR)}

The cells were cultured in AS- 168 medium at $37^{\circ} \mathrm{C}$ for $12 \mathrm{~h}$ and subsequently harvested by centrifugation $(12,000 \times g$, $\left.4^{\circ} \mathrm{C}\right)$. The total RNA was extracted using TRIzol reagent (Invitrogen, United States) as previously described (Lu et al., 2008a). TURBO DNA-free ${ }^{\text {TM }}$ Kit (Thermo Fisher Scientific, United States) was used for removing DNA contamination. The cDNA was synthesized by reverse transcription with random hexamer primers from $1 \mu \mathrm{g}$ of DNA-free total RNA using the Moloney Murine Leukemia Virus Reverse Transcriptase (M MLV-RT) (Promega, United States). The relative fold of gene expression was analyzed by $\mathrm{ViiA}^{\mathrm{TM}} 7$ Real-Time PCR System (Applied Biosystems, Inc., United States), using 7S RNA as an endogenous control to normalize the data of each sample. The primers used are listed in Supplementary Table S2.

\section{Sequences Analysis and Databases}

The DNA sequences were obtained from National Center for Biotechnology Information (NCBI) Genome Database. The information about the most identified enzymes involved in MVA and lycopene synthesis pathway (supported by evidence at protein level), was accessed from UniProt Database ${ }^{1}$. Sequence homology was assessed by BLASTN or BLASTP in NCBI (Altschul et al., 1990). Predictions of transmembrane helices in the proteins were performed by using the TMHMM Server v2. $0^{2}$ (Krogh et al., 2001).

The genome accession numbers deposited in GenBank are as following, $H$. mediterranei (CP001868.2), H. hispanica (NC_015948.1), and H. salinarum (AM774415.1).

\section{Statistical Analysis}

Experiments were performed in triplicate and data was analyzed by the GraphPad Prism 7 software and represented as mean \pm standard deviation. Statistical analysis was done

${ }^{1}$ http://www.uniprot.org/

${ }^{2}$ http://www.cbs.dtu.dk/services/TMHMM/ using a two-tailed $t$-test. Statistical significance was defined as ${ }^{*} p<0.05$.

\section{RESULTS}

\section{Identifying the Rate-Limiting Steps Involved in Native Lycopene Biosynthesis}

In silico metabolic pathway analysis reveals that $H$. mediterranei has a complete lycopene biosynthetic pathway, referring to the steps from isopentenyl-PP (IPP) and dimethylallyl-PP (DMAPP) to lycopene (Figure 2). Mevalonate (MVA) pathway provides the two important precursors, IPP and DMAPP, for lycopene synthesis. In MVA pathway, two molecules of acetyl-CoA are condensed to form acetoacetyl-CoA and a third acetyl-CoA molecule is then added to form 3-hydroxy-3-methylglutaryl-CoA (HMG-CoA) by Hydroxymethylglutaryl-CoA synthase (MvaB, HFX_2424). The next step involves the conversion of HMGCoA to MVA by Hydroxymethylglutaryl-CoA reductase (HmgR, HFX_2609). MVA is then phosphorylated by Mevalonate kinase (Erg12, HFX_2773) to generate mevalonate phosphate (MVAP). Different from the classical MVA pathway, an alternative pathway is proposed for the IPP generation from MVAP, which is catalyzed by Diphosphomevalonate decarboxylase (DmD, HFX_1486) and Isopentenyl phosphate kinase (IpK, HFX_2774). IPP can be then isomerized to DMAPP by Isopentenyl-diphosphate deltaisomerase (IdI, HFX_2519). DMAPP and IPP are condensed to geranyl-PP (GPP) and then to farnesyl-PP (FPP) and finally to geranylgeranyl-PP (GGPP) by trifunctional prenyl diphosphate synthase (IdsA, HFX_2735). Two molecules of GGPPs are condensed by CrtB (HFX_2547) to form phytoene and then it undergoes four consecutive desaturation reactions catalyzed by CrtI (HFX_2550) to produce lycopene.

Although $H$. mediterranei possessed the complete lycopene synthetic pathway, we could not detect lycopene accumulation in this strain (Figure 3B). The extremely low lycopene production might be due to the rate-limiting steps in its lycopene biosynthesis. According to the previous studies about ratelimiting steps in MVA and lycopene synthesis pathway (Goldstein and Brown, 1990; Kang et al., 2005; Steussy et al., 2005; Anthony et al., 2009; Lombard and Moreira, 2011; Berthelot et al., 2012), we selected all the predicted genes as our candidates to be overexpressed in $H$. mediterranei (Figure 2 and Table 1). To rapidly identify the rate-limiting steps, we used a plasmidbased expression system for candidate genes overexpression under the control of a strong constitutive promoter $\mathrm{P}_{\mathrm{phaR}}$. The expression plasmid containing each gene was transformed into the strain DF50 $\Delta$ eps (Zhao et al., 2013) individually and correct transformants were confirmed by PCR and Sanger sequencing. Functional overexpression of the genes encoding rate-limiting enzymes made transformants orange or even red, so it was easy to identify the genes encoding rate-limiting enzymes. Obviously, only the overexpression of gene $\operatorname{crt} B_{\mathrm{hm}}$ resulted in an orange colored phenotype (Figure 3A). Meanwhile the lycopene accumulation in this $\mathrm{crt} B_{\mathrm{hm}}$-overexpressed strain DF50-2547 was further confirmed by HPLC (Figure 3B), whereas no lycopene accumulation was detected in other gene overexpressed strains 


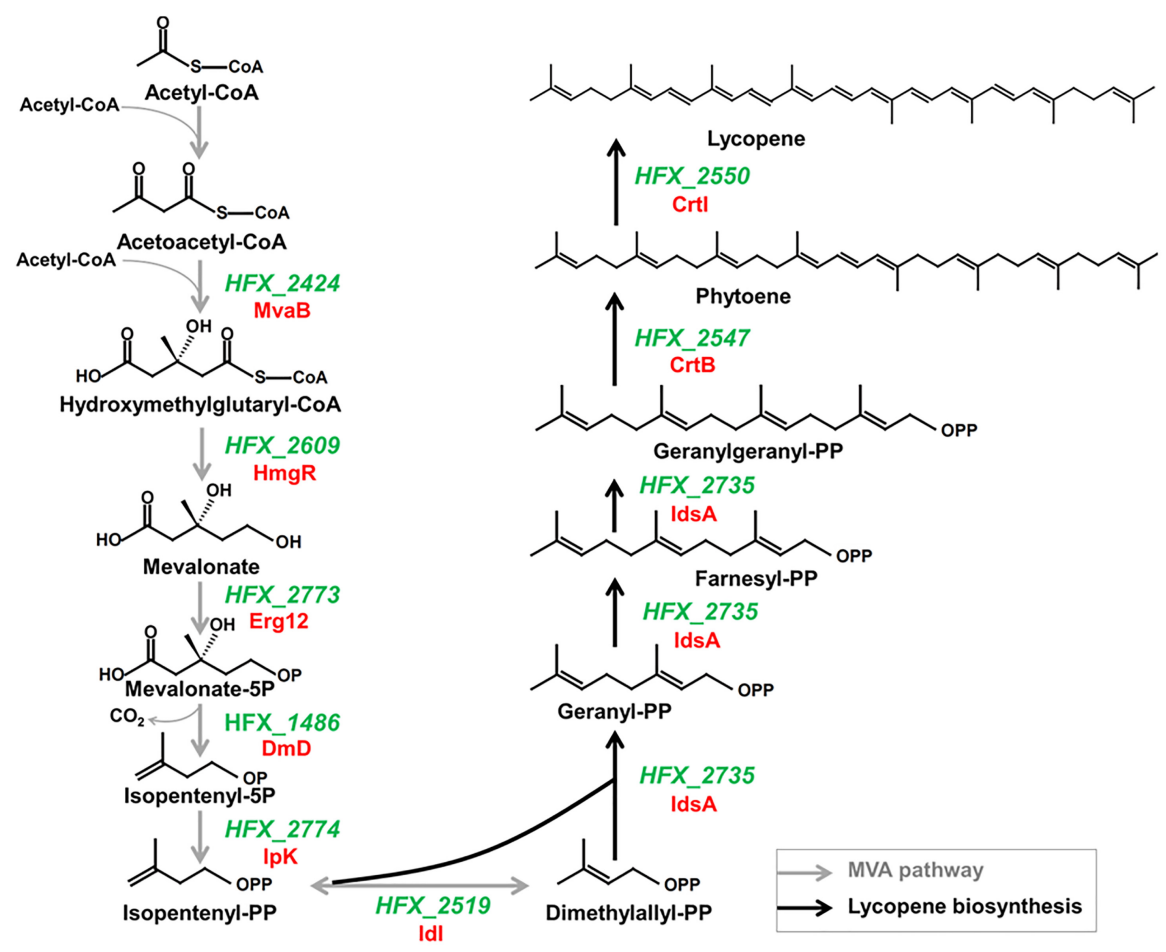

FIGURE 2 | Proposed main steps in the mevalonate and lycopene biosynthesis pathways of $H$. mediterranei based on the KEGG pathway database. For simplicity, cofactors and ATP consumption are not shown. Gray arrows show the MVA pathway and black ones show the lycopene biosynthetic pathway descripted in this study.

\section{A}

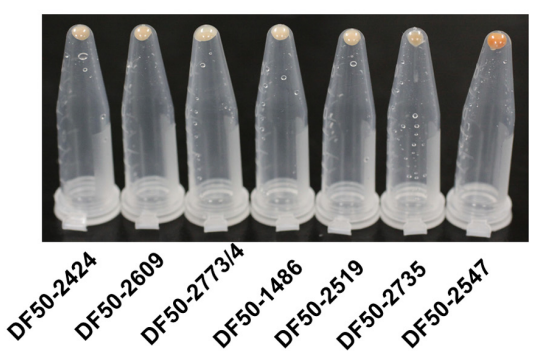

B

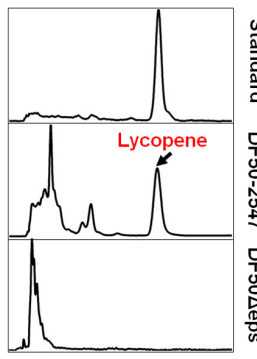

C

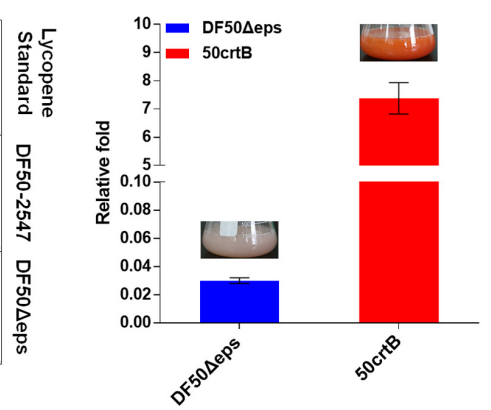

FIGURE 3 | Identification of the rate-limiting steps involved in lycopene biosynthesis in $H$. mediterranei. (A) Collected $H$. mediterranei cells (1 mL) with a single gene overexpressed in eppendorf tubes. HFX_2773 and HFX_2774 are overlapped by four nucleotides and thus they are co-expressed. (B) HPLC analysis of the lycopene produced by DF50-2547 and DF50 $\Delta$ eps. (C) qRT-PCR analysis of $\mathrm{crt} \mathrm{hm}_{\mathrm{hm}}$ transcriptional level in DF50 $\Delta$ eps and $50 \mathrm{crtB}$. The relative fold of $c r t B_{\mathrm{hm}}$ gene expression level is calculated by normalization to the expression of inner control 7S RNA. Insets are the photographs of 7-day shake flask cultures.

(Supplementary Figure S2). These results indicated that the step from GGPP to phytoene was the rate-limiting step in lycopene synthesis in $H$. mediterranei.

\section{Reinforcing the Rate-Limiting Step in Lycopene Synthesis by Insertion of a Strong Promoter}

The plasmid-based overexpression of $c r t B_{\mathrm{hm}}$ could reinforce the rate-limiting step and thus enhanced the production of lycopene in $H$. mediterranei. However, this plasmid-based system is not genetically stable and probably brings a metabolic burden. To address this issue, we therefore constructed the plasmid pHFXB (Supplementary Table S1) and used a twostep homologous recombination method to insert promoter $\mathrm{P}_{\text {phaR }}$ into the chromosome immediately up-stream of $\mathrm{crt} B_{\mathrm{hm}}$ in DF50 $\Delta$ eps. The engineered strain, termed $50 \mathrm{crtB}$, was easy to be distinguished visually, because of its orange color, which was different from the light pink color of its parental strain DF50 $\Delta$ eps (Figure 3C). 
TABLE 1 | Identity analysis between candidate enzymes involved in lycopene biosynthesis in $H$. mediterranei and idendified enzymes.

\begin{tabular}{|c|c|c|c|c|}
\hline \multicolumn{2}{|c|}{$\begin{array}{l}\text { Enzyme in } \\
\text { H. mediterranei }\end{array}$} & \multicolumn{2}{|c|}{ Identified enzymes } & \multirow[t]{2}{*}{$\begin{array}{l}\text { Protein } \\
\text { identity }\end{array}$} \\
\hline Enzyme & Gene & Gene & Reference strain & \\
\hline MvaB & HFX_2424 & HVO_2419 & $\begin{array}{l}\text { H. vocanii (VanNice } \\
\text { et al., 2013) }\end{array}$ & $95 \%$ \\
\hline HmgR & HFX_2609 & HVO_2583 & $\begin{array}{l}\text { H. vocanii (Bischoff } \\
\text { and Rodwell, 1996) }\end{array}$ & $89 \%$ \\
\hline Erg12 & HFX_2773 & HVO_2761 & $\begin{array}{l}\text { H. vocanii (Azami } \\
\text { et al., 2014) }\end{array}$ & $92 \%$ \\
\hline $\mathrm{DmD}$ & HFX_1486 & HVO_1412 & $\begin{array}{l}\text { H. vocanii (VanNice } \\
\text { et al., 2014) }\end{array}$ & $90 \%$ \\
\hline IpK & HFX_2774 & HVO_2762 & $\begin{array}{l}\text { H. vocanii (VanNice } \\
\text { et al., 2014) }\end{array}$ & $89 \%$ \\
\hline Idl & HFX_2519 & $i d i$ & $\begin{array}{l}\text { E. coli (Hemmi } \\
\text { et al., 1998) }\end{array}$ & $32 \%$ \\
\hline \multirow[t]{2}{*}{ IdsA } & HFX_2735 & ispA & $\begin{array}{l}\text { E. coli (Hosfield } \\
\text { et al., 2004) }\end{array}$ & $31 \%$ \\
\hline & & crtE & E. vulneris & $30 \%$ \\
\hline CrtB & HFX_2547 & crtB & $\begin{array}{l}\text { Synechococcus } \\
\text { elongatus } \\
\text { (Chamovitz et al., } \\
\text { 1992) }\end{array}$ & $32 \%$ \\
\hline Crtl & HFX_2550 & crtl & $\begin{array}{l}\text { Erwinia uredovora } \\
\text { (Fraser et al., 1992) }\end{array}$ & $31 \%$ \\
\hline
\end{tabular}

Next, we analyzed the transcription level of $\operatorname{crt} B_{\mathrm{hm}}$ in strain $50 \mathrm{crtB}$ and DF50 $\Delta$ eps by qRT-PCR. The result showed that the insertion of promoter $\mathrm{P}_{\mathrm{phaR}}$ dramatically increased the transcription level of $c r t B_{\mathrm{hm}}$ by 245 times, when compared with the DF50 $\Delta$ eps strain (Figure 3C). As expected, the high $\mathrm{CrtB}_{\mathrm{hm}}$ expression level significantly promoted the conversion from GGPP to phytoene and subsequently improved lycopene biosynthesis. After cultivation in shake flasks containing $50 \mathrm{~mL}$ MG medium for 7 days, a lycopene production of $6.05 \pm 0.18 \mathrm{mg} / \mathrm{g}$ dry cell weight $(\mathrm{DCW})(35.15 \pm 0.43 \mathrm{mg} / \mathrm{L})$ was achieved (Figure 4C).

\section{Disrupting Bacterioruberin Biosynthesis to Improve the Accumulation and Purity of Lycopene}

Lycopene is the last shared intermediate in bacterioruberin and retinal biosynthesis in some haloarchaea (Peck et al., 2017). However, H. mediterranei lacks the genes, $\operatorname{crt} Y$ (encoding lycopene cyclase) (Peck et al., 2002), brp and blh (encoding $\beta$-carotene dioxygenase) (Peck et al., 2001), involved in the retinal biosynthesis pathway and therefore, lycopene can only flux into bacterioruberin biosynthesis (Figure 1A). Thus, we next blocked bacterioruberin biosynthesis to enhance lycopene accumulation and its purity. Bioinformatic analysis revealed the presence of two genes (HFX_1501 and HFX_2549) potentially involved in bacterioruberin synthesis in $H$. mediterranei. Both of them are annotated as putative prenyltransferases, which can transfer 5-carbon prenyl groups to various substrates. HFX_1501 encodes a protein of 284 amino acid residues, which showed 30 and $28 \%$ identity to the LyeJ of $H$. salinarum and $H$. japonica, respectively (Supplementary Figure S3A). In the case of HFX_2549, it encodes a 292-amino acid protein exhibiting 64 and 61\% identity to the LyeJ of $H$. salinarum and $H$. japonica, respectively (Supplementary Figure S3B). Moreover, it is located within the carotenoid biosynthetic gene cluster. Furthermore, a membrane topology analysis using TMHMM revealed that HFX_2549 encoded an integral membrane protein containing seven transmembrane domains (Supplementary Figure S3B), consistent with the LyeJ of $H$. salinarum or $H$. japonica. This suggested that HFX_2549 is likely to encode LyeJ in H. mediterranei.

We knocked out the gene, HFX_2549, and obtained the strain $50 \mathrm{~B} \Delta 2549$. The carotenoid components of the $50 \mathrm{crtB}$ and 50B $\Delta 2549$ strains were analyzed qualitatively by TLC. The sample from $50 \mathrm{crtB}$ displayed multiple spots on the silica plate (Figure 4A, Spots 1-4), which represented lycopene, bacterioruberin and its derivates. In contrast, the sample from 50B $\Delta 2549$ only contained a single spot 1 (Figure 4A, Spot 1). Subsequently, spot 1 on the silica plate from the
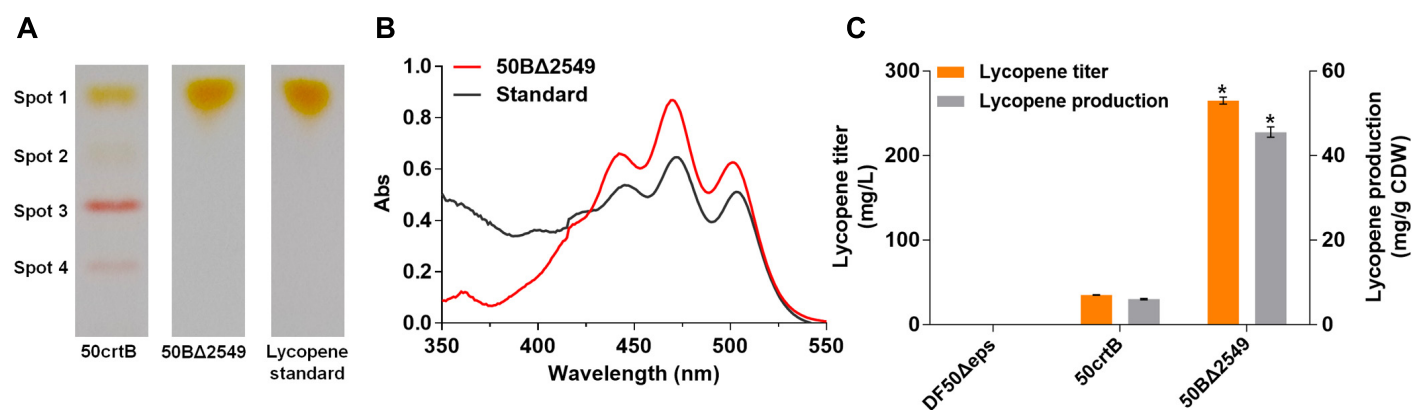

FIGURE 4 | Analysis of lycopene production of 50crtB and 50B $\Delta 2549$. (A) TLC analysis of the carotenoids extracted from 50crtB and 50B $\Delta 2549$. Spot 1 contains mainly lycopene, Spot 2-Spot 4 consists of bacterioruberin and its derivates. (B) UV-Vis absorption spectra of the carotenoids extracted from the pigment spot of $50 B \Delta 2549 \mathrm{in} \mathrm{TLC}$ plate. The wavelength range is set as $350 \sim 550 \mathrm{~nm}$. (C) Lycopene titer and production of 50crtB and 50B 2549 . Strains are cultured for 7 days in $50 \mathrm{~mL}$ MG medium at $37^{\circ} \mathrm{C}$ in shake flasks. ${ }^{*} p<0.05$, lycopene production and titer of the group $50 \mathrm{~B} \Delta 2549$ are compared with the $50 \mathrm{crtB}$. Data is expressed as Mean \pm SD of triplicate determinations. 
50B $\Delta 2549$ strain was recovered and extracted by using acetone. The UV-Vis absorbance spectrum of the extracted sample had a typical three-finger shape of lycopene at 442, 470 and $501 \mathrm{~nm}$, similar to the absorption spectrum of lycopene standard (Figure 4B). These results indicated that 50B $\Delta 2549$ could not synthesize bacterioruberin and its derivates, and the reaction was terminated at the lycopene step. Consequently, HFX_2549 was the key enzyme for bacterioruberin synthesis in $H$. mediterranei. Lycopene production of 50B $\Delta 2549$ was further quantified by HPLC. The production significantly increased to $45.54 \pm 1.23 \mathrm{mg} / \mathrm{g} \mathrm{DCW}$, which was about 6.5 times higher than that of $50 \mathrm{crtB}$ (Figure 4C).

\section{Lycopene Production Improvement by Importing Phytoene Desaturase From Other Haloarchaea}

To improve the yield of the target products, it is often necessary to enhance the availability of essential precursors (Xie et al., 2015a). In our study, overexpression of $\mathrm{crt} B_{\mathrm{hm}}$ supplied more precursor, phytoene, for lycopene synthesis, and enhancement of the flux from phytoene to lycopene is another strategy for lycopene production improvement. Here, we strengthened the process by importing heterologous gene $c r t I_{\text {ha }}$ or $c r t I_{\text {hs }}$ from carotenogenic haloarchaea, $H$. hispanica or $H$. salinarum. First, we confirmed the function of $c r t I_{\mathrm{ha}}$ and $c r t I_{\mathrm{hs}}$ by transforming their expression plasmid pWHA1058 or pWOE3381 (Supplementary Table S1) into the $50 \mathrm{~B} \Delta 2549$ strain. The positive transformants with the functional expression of heterologous crtI showed enhanced color intensity (Figure 5A). Afterward, we constructed two plasmids, pHI6 and pHIH (Supplementary Table S1), for the integration of $c r t I_{\mathrm{ha}}$ and $c r t I_{\mathrm{hs}}$ into the chromosome of $H$. mediterranei (Supplementary Figure S1A). To avoid unpredictable effects brought by the insertion site, we used $50 \mathrm{crtB}$ as the host and integrated these two genes separately in the chromosome by replacing HFX_2549 (Figure 1B). The two resultant strains were named 50BI6 and 50BIH (Supplementary Table S1).

Lycopene production by the engineered strains were then determined by HPLC. Lycopene yields of $56.46 \pm 0.74 \mathrm{mg} / \mathrm{g}$ DCW $(292.21 \pm 2.88 \mathrm{mg} / \mathrm{L})$ and $49.37 \pm 2.95 \mathrm{mg} / \mathrm{g}$ DCW $(271.43 \pm 6.07 \mathrm{mg} / \mathrm{L})$ were obtained in the engineered strains, $50 \mathrm{BI} 6$ and 50BIH, respectively. This result showed that the heterologous expression of $\mathrm{crtI}_{\mathrm{ha}}$ in $\mathrm{H}$. mediterranei was more effective for enhancing lycopene synthesis compared to $c r t I_{\mathrm{hs}}$. Finally, 50BI6 got a $24.0 \%$ increase in lycopene production and $10.2 \%$ increase in lycopene titer compared to $50 \mathrm{~B} \Delta 2549$ (Figure 5C).

\section{Heterologous crtB Overexpression for Further Optimizing Lycopene Production}

The high lycopene production strain 50BI6 contained two copies of $c r t I\left(c r t I_{\mathrm{hm}}\right.$ and $\left.c r t I_{\mathrm{ha}}\right)$. To investigate whether CrtB was still the rate-limiting enzyme in 50BI6, another copy of crtB from $H$. hispanica or $H$. salinarum was introduced into 50BI6. We constructed two types of $c r t B$ - $c r t I$ expression cassettes, $\operatorname{crt} B_{\mathrm{ha}^{-}}$ $c r t I_{\text {ha }}$ and $c r t B_{\mathrm{hs}}-c r t I_{\text {ha }}$ (Figure 5B) and inserted these expression

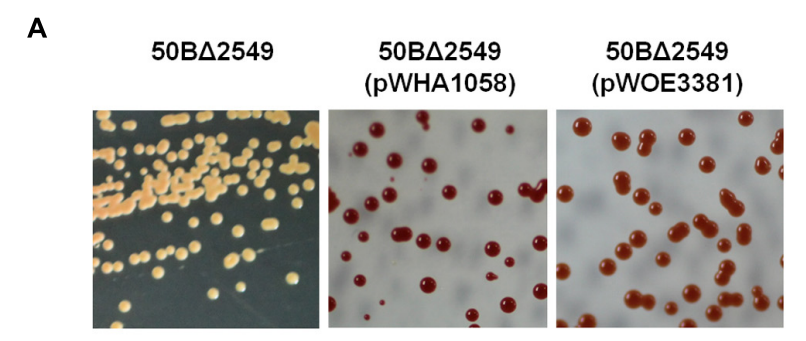

B
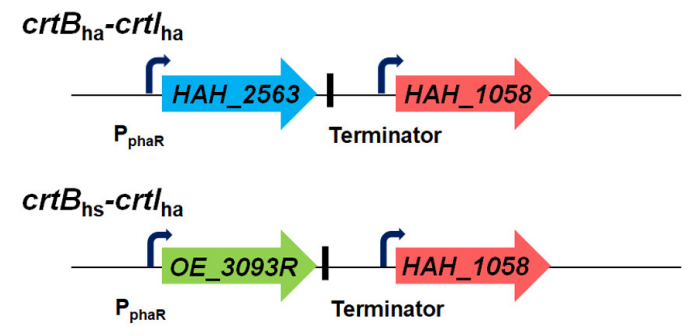

C

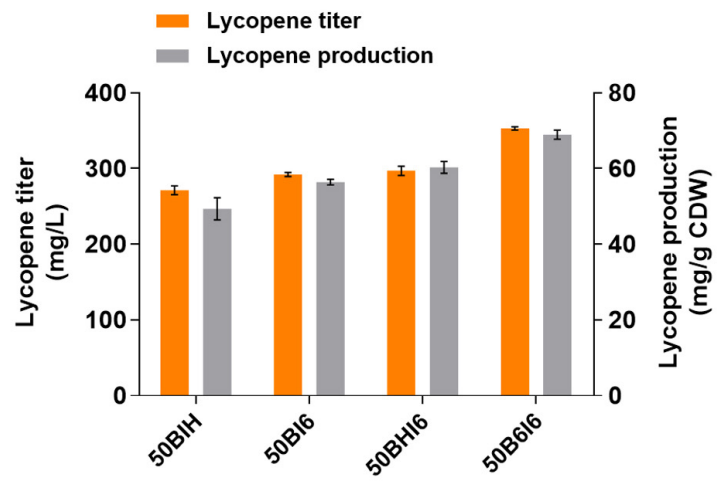

FIGURE 5 | Importation of heterologous crt genes to improve lycopene production. (A) Colony color of $H$. mediterranei 50B $\Delta 2549$ cultured in AS-168 medium and the strains after introducing the expression plasmid containing crtl from Haloarcula hispanica or Halobacterium salinarum cultured in AS-168Y medium. 50B $\Delta 2549$ with pWHA1058 means crt/ha expressed strain and pWOE3381 means $\mathrm{crt} / \mathrm{hs}$ expressed strain. (B) $\mathrm{crtB}$-crtl expression cassettes. Each gene was under the control of $\mathrm{P}_{\text {phan }}$ promoter and $\mathrm{a}$ terminator was in the downstream of $\mathrm{crtB}$ ha or crtBhs. (C) Lycopene titer and production of engineered $\mathrm{H}$. mediterranei by insertion of heterologous $\mathrm{Crt}$ genes in the chromosome of 50crtB by replacing HFX_2549. Strains are cultured for 7 days in $50 \mathrm{~mL} \mathrm{MG}$ medium at $37^{\circ} \mathrm{C}$ in shake flasks.

cassettes in the chromosome of 50crtB by replacing HFX_2549 to obtain new strains, 50B6I6 and 50BHI6 (Figure 1B and Supplementary Figure S1B). We analyzed the transcriptional status of $c r t B_{\mathrm{ha}}, c r t B_{\mathrm{hs}}$, and $c r t I_{\mathrm{ha}}$ in these two strains and found that all the expected genes were successfully transcribed base on the RT-PCR analysis (Supplementary Figure S4). The lycopene yields of 50B6I6 and 50BHI6 were further increased to $68.95 \pm 1.19 \mathrm{mg} / \mathrm{g} \mathrm{DCW}(353.06 \pm 2.39 \mathrm{mg} / \mathrm{L})$ and $60.33 \pm 1.56 \mathrm{mg} / \mathrm{g}$ DCW (297.05 $\pm 6.50 \mathrm{mg} / \mathrm{L})$, respectively (Figure 5C). This suggested that the strains with co-introduced $\operatorname{crt}_{\mathrm{h}}$ and $c r t I_{\text {ha }}$ could produce more lycopene. Lycopene titer displayed a $20.8 \%$ increase in 50B6I6 compared to 50BI6. 


\section{Disruption of PHBV Biosynthesis to Divert More Acetyl-CoA Flux to Lycopene}

$H$. mediterranei can accumulate a large amount of PHBV when cultured in MG medium (Zhao et al., 2013) and acetyl-CoA is an important precursor for its biosynthesis (Don et al., 2006). Blocking acetyl-CoA flux to PHBV biosynthesis may be able to further maximize the lycopene production (Figure 1B). To prove this, we knocked out the PHBV synthase encoding genes, phaE and phaC ( $\mathrm{Lu}$ et al., 2008b), in 50B6I6 and obtained a new strain, named 50B6I6 $\Delta$ phaEC (Supplementary Table S1). It could not produce PHBV as determined by gas chromatography (Table 2) and this result suggested that the deletion of phaEC blocked PHBV synthesis. Moreover, HPLC analysis showed that $50 \mathrm{~B} 6 \mathrm{I} 6 \Delta$ phaEC synthesized lycopene with a production level of $119.25 \pm 0.55 \mathrm{mg} / \mathrm{g} \mathrm{DCW}$, which was $73.0 \%$ higher than that of 50B6I6. Meanwhile, lycopene titer of 50B6I6 $\Delta$ phaEC increased to $429.41 \pm 5.81 \mathrm{mg} / \mathrm{L}$, which was $21 \%$ enhancement compared to 50B6I6. This result indicated that the disruption of PHBV biosynthesis could enhance the acetyl-CoA flux to lycopene biosynthesis.

\section{Effect of Auxotrophy on Lycopene Production}

In this work, all the genetic manipulation was based on the pyrF-deleted strain DF50 $\Delta$ eps (uracil auxotrophic mutant). Uracil addition was required to culture these engineered strains in MG medium. However, this approach was not suitable for high-cell density fermentation and increased the production cost. To address this issue, we restored the functional expression of $p y r F$ in 50B6I6 $\Delta$ phaEC. A linear DNA fragment containing $p y r F$ and homologous arms, $500 \mathrm{bp}$ in up-stream or down-stream of $p y r F$, was amplified by PCR using the genomic DNA of $H$. mediterranei as a template and transferred into the 50B6I6 $\Delta$ phaEC strain. The screening process was carried out using AS-168SY medium, in which the negative colonies could not grow. We obtained the correct pyrF complementary strain 50FB6I $6 \Delta$ phaEC and it gave a lycopene yield of $107.37 \pm 2.37 \mathrm{mg} / \mathrm{g}$ DCW $(396.70 \pm 13.39 \mathrm{mg} / \mathrm{L})$, while there was no difference in biomass between $50 \mathrm{~B} 6 \mathrm{I} 6 \Delta \mathrm{phaEC}$ and $50 F B 6 I 6 \Delta$ phaEC (Figure 6). Although the complementation of pyrF did not increase the biomass and led to a little decrease in lycopene content, 50FB6I6 $\Delta$ phaEC could be cultured in MG medium without uracil, which was more feasible for industrial application.

TABLE 2 | PHBV content and lycopene production in 50B616 and $50 \mathrm{~B} 616 \Delta \mathrm{phaEC}$.

\begin{tabular}{lccc}
\hline \multirow{2}{*}{ Strains } & PHBV $\%$ & \multicolumn{2}{c}{ Lycopene } \\
\cline { 3 - 4 } & & Titer $(\mathbf{m g} / \mathbf{L})$ & Production $\mathbf{( m g / g )}$ \\
\hline $50 B 616$ & $62.84 \pm 1.11$ & $353.06 \pm 2.39$ & $68.95 \pm 1.19$ \\
$50 B 616 \Delta$ phaEC & 0 & $429.41 \pm 5.81$ & $119.25 \pm 0.55$
\end{tabular}

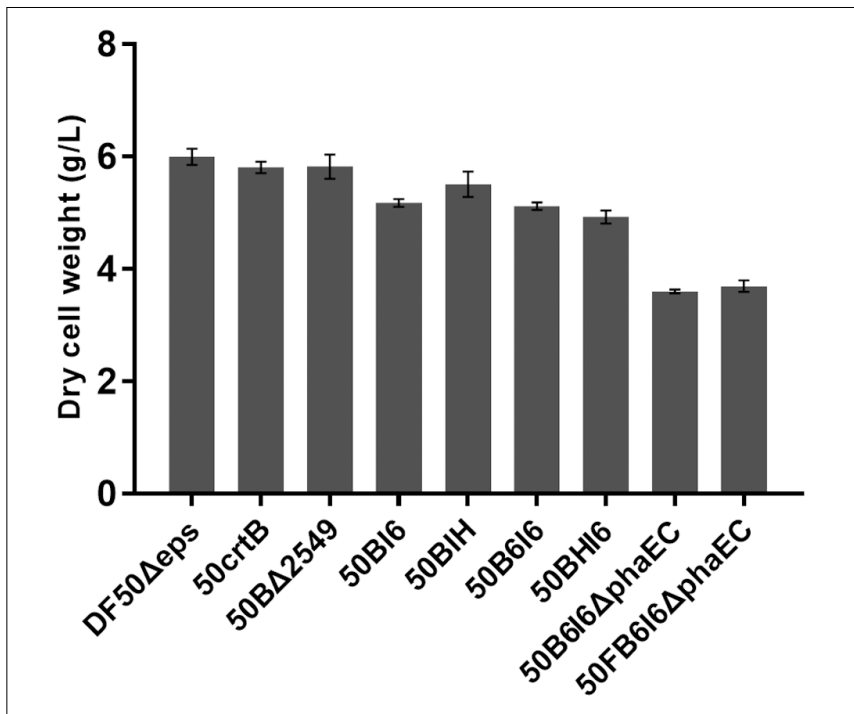

FIGURE 6 | Dry cell weights of engineered $H$. mediterranei strains.

\section{DISCUSSION}

Regarding to food safety issues, lycopene from natural source, such as watermelon, gac fruit, tomato, and so on (PerkinsVeazie and Davis, 2004; Viuda-Martos et al., 2014; Lv et al., 2015; Papaioannou et al., 2016; Wimalasiri et al., 2017), is superior to that from chemical synthesis. Among these fruits or vegetables, tomato is a major source of lycopene, but its total lycopene content is too low to meet the market requirements. Multiple strategies of engineering the carotenoid synthesis pathway in tomato fruit to improve its lycopene content were adopted in several studies. Fraser et al. (2002) introduced an additional crtB from Erwinia uredovora into tomato in a fruit-specific manner and obtained a 1.8 -fold increase of lycopene content. Enfissi et al. (2005) got a 1.6-fold increase of lycopene content by overexpression of a bacterial 1-deoxy-Dxylulose-5-phosphate synthase (DXS) encoding gene. Namitha and Negi (2018) introduced a bacterial crtY gene from Pantoea agglomerans into tomato fruit to enhance lycopene production by 2.1 -fold. In addition, other strategies were also used to alter carotenoid content in tomato fruit. Overexpression of blue light photoreceptor, cryptochrome 2, resulted in a 1.7fold increase of lycopene content in tomato fruit (Giliberto et al., 2005). Importing the pepper fibrillin gene into tomato fruit led to a $118 \%$ increase in lycopene level (Simkin et al., 2007). Additionally, Mehta et al. (2002) demonstrated that higher level of polyamines in tomato fruit by fruit-specific overexpression of a yeast $S$-adenosylmethionine decarboxylase gene $(y S A M d c)$ enhanced the lycopene content by $2 \sim 3$ folds in tomato fruit. In the same way, Neily et al. (2011) overexpressed the spermidine synthase gene in tomato and also got an unexpected increase of $1.3 \sim 2.2$ folds in lycopene prodcution. The increased polyamines were revealed to affect multiple cell pathways and broad gene expression levels, thereby enhancing lycopene accumulation (Mattoo et al., 2006, 2007; 
Kolotilin, 2008; Kolotilin et al., 2011; Neily et al., 2011; Guo et al., 2018). However, these transgenic plants are still far from large-scale industrial application for lycopene production (Table 3). Lycopene production by microbial fermentation is an attractive alternative to use of plants. Moreover, the strains also need to be engineered for improving its production to make the fermentation process more cost competitive. In engineered E. coli, the highest lycopene production of $448 \mathrm{mg} / \mathrm{g}$ DCW was obtained by employing a new combinatorial multi-gene pathway assembly scheme (Coussement et al., 2017). In yeast, through engineering host and pathway, the highest lycopene yield, $55.56 \mathrm{mg} / \mathrm{g}$ DCW was achieved in 5-L bioreactors (Chen et al., 2016). In B. trispora, a lycopene production of $103.58 \mathrm{mg} / \mathrm{g}$ DCW was realized by the modification of the bifunctional gene, $\operatorname{car} R A$, combined with addition of tripropylamine (Wang et al., 2017). In this study, a carotenogenic haloarchaea, $H$. mediterranei was chosen as a novel chassis cell for lycopene overproduction, due to its several superior features, such as high salt tolerance capability, easy lysis, etc. These can contribute to reduce the energy cost brought by strict sterilization and to simplify the process for lycopene extraction. We adopted multiple strategies to engineer $H$. mediterranei for lycopene production enhancement and finally our best strain gave a lycopene yield of $119.25 \mathrm{mg} / \mathrm{g}$ DCW, which was even higher than the yields of most well-studied strains (Table 3). Although engineered E. coli produced the highest level of lycopene, it is controversial to use it for lycopene synthesis, since this strain would release endotoxin (Ray and Raetz, 1987). In contrast, haloarchaea has an extremely low endotoxin level because of its special structure of cell envelope (Xue et al., 2018). Thus, $H$. mediterranei is a promising microbial host for lycopene biosynthesis.

However, in optimal culture conditions for growth, $H$. mediterranei, is less pigmented and no lycopene can be detected (Figure 3B). This might be due to the presence of a rate-limiting step involved in lycopene synthesis. Then we investigated the overexpression of the possible rate-limiting enzyme encoding genes in the MVA and lycopene synthesis pathway and found that only $\operatorname{crtB}$ overexpression resulted in significant lycopene accumulation. This result suggested that the MVA pathway in $H$. mediterranei is efficient to produce essential precursors of IPP and DMAPP for lycopene synthesis. Thus, in the next step, the first strategy we adopted to improve lycopene production was reinforcing lycopene synthesis pathway. First, we eliminated the rate-limiting step by inserting a strong promoter in the chromosome ahead of $\operatorname{crtB}$ and realized a lycopene production of $6.05 \mathrm{mg} / \mathrm{g}$ DCW. Then to avoid the limitation of final target products, brought by insufficient ability of downstream pathway (Leonard et al., 2010), we imported heterologous $c r t I$ and enhanced the lycopene production to $56.46 \mathrm{mg} / \mathrm{g}$ DCW. Next, we integrated heterologous haloarchaeal crtB-crtI cassettes into the chromosome and got a lycopene yield of $68.95 \mathrm{mg} / \mathrm{g}$ DCW. Similarly, Xie et al. (2015a) adjusted the

TABLE 3 | Summary of lycopene production in transgenic plant and engineered microorganisms.

\begin{tabular}{|c|c|c|c|c|}
\hline Organism & Strategies & Culture condition & Lycopene production & Reference \\
\hline \multicolumn{5}{|l|}{ Plant } \\
\hline Tomato & $\begin{array}{l}\text { Engineering carotenoids synthesis } \\
\text { pathway }\end{array}$ & Grown in the glasshouse & $5.22 \mathrm{mg} / \mathrm{g} \mathrm{DCW}$ & Fraser et al., 2002 \\
\hline Tomato & & Grown in the glasshouse & $6.7 \mathrm{mg} / \mathrm{g}$ DCW & Enfissi et al., 2005 \\
\hline Tomato & & Grown in green house & $\sim 0.11 \mathrm{mg} / \mathrm{g} \mathrm{DCW}$ & Namitha and Negi, 2018 \\
\hline Tomato & $\begin{array}{l}\text { Manipulation of the blue light } \\
\text { photoreceptor cryptochrome } 2\end{array}$ & Grown in green house & 1.35 mg/g DCW & Giliberto et al., 2005 \\
\hline Tomato & $\begin{array}{l}\text { Importing the pepper fibrillin gene in } \\
\text { tomato }\end{array}$ & Grown in green house & $\sim 0.48 \mathrm{mg} / \mathrm{g} \mathrm{FW}{ }^{*}$ & Simkin et al., 2007 \\
\hline Tomato & $\begin{array}{l}\text { Enhancement of polyamine } \\
\text { accumulation }\end{array}$ & Grown in green house & $\sim 0.11 \mathrm{mg} / \mathrm{g} \mathrm{FW}{ }^{*}$ & Mehta et al., 2002 \\
\hline Tomato & & Grown in green house & 1.72 mg/g DCW & Neily et al., 2011 \\
\hline \multicolumn{5}{|l|}{ Microbe } \\
\hline $50 \mathrm{~B} 6 \mathrm{l} 6 \Delta \mathrm{phaEC}$ & Pathway engineering & Shake flask fermentation & 119.25 mg/g DCW & This study \\
\hline E. coli & & Microtiter plate fermentation & 448 mg/g DCW & Coussement et al., 2017 \\
\hline E. coli & Chromosomal evolution & Shake flask fermentation & 33.4 mg/g DCW & Chen et al., 2013 \\
\hline E. coli & Pathway balancing & Fed-batch fermentation & $43.7 \mathrm{mg} / \mathrm{g}$ DCW & Zhu et al., 2015 \\
\hline E. coli & $\begin{array}{l}\text { Pathway engineering combined with } \\
\text { NADPH and ATP balancing }\end{array}$ & Fed-batch fermentation & $50.6 \mathrm{mg} / \mathrm{g}$ DCW & Tao et al., 2014) \\
\hline E. coli & $\begin{array}{l}\text { Plasmid based overexpression of } \\
\text { carotenoids synthesis genes }\end{array}$ & Shake flask fermentation & 67 mg/g DCW & Xu et al., 2018 \\
\hline S. cerevisiae & $\begin{array}{l}\text { Directed evolution and metabolic } \\
\text { engineering }\end{array}$ & Fed-batch fermentation & $24.41 \mathrm{mg} / \mathrm{g} \mathrm{DCW}$ & Xie et al., 2015a \\
\hline S. cerevisiae & Pathway engineering & Fed-batch fermentation & 55.56 mg/g DCW & Chen et al., 2016 \\
\hline Yarrowia lipolytica & & Fed-batch fermentation & $21.1 \mathrm{mg} / \mathrm{g}$ DCW & Schwartz et al., 2017 \\
\hline B. trispora & $\begin{array}{l}\text { Genetically manipulated the bifunctional } \\
\text { protein gene, carRA }\end{array}$ & Shake flask fermentation & 103.58 mg/g DCW & Wang et al., 2017 \\
\hline
\end{tabular}

*FW, fresh weight. 
copy number of crt genes to get more than $80 \%$ increase of lycopene production in Saccharomyces cerevisiae. They reported that multiple copies of crt genes led to an about $13 \%$ decrease in biomass (Xie et al., 2015a). Similar results were also obtained in the present study (Figure 6). The dry cell weight of the engineered strains 50BI6, 50BIH, 50B6I6, and 50BHI6 showed a decrease of about $10 \%$. This might be due to the metabolic burden brought by the overexpression of crt genes. However, the significant increase of lycopene titer overweighed the slight biomass decrease in these engineered strains.

The second strategy we used is disruption of the lycopene flux to other carotenoids or deletion of the competing pathways sharing common precursors with the lycopene synthetic pathway. Wang et al. (2016) inhibited the activity of lycopene cyclase, the enzyme responsible for conversion of lycopene to $\beta$-carotene, and increased the lycopene content by $90.1 \%$. In E. coli, the knockout of $g d h A, a c c E$, and $f d h F$ gave a $37 \%$ increase in lycopene content (Alper et al., 2005). In this work, we knocked out the gene lyeJ to block the bacterioruberin biosynthesis and thus improved the lycopene purity and got a 6.5-fold increase of lycopene production. MVA pathway commences with acetylCoA, which is also the important precursor for PHBV synthesis in $H$. mediterranei. Removing the competing pathways for lycopene synthesis can theoretically facilitate lycopene accumulation. So we disrupted the PHBV synthesis in H. mediterranei, by deleting the key genes phaE and phaC. As expected, the engineered strain 50B6I6 $\Delta$ phaEC did not synthesis PHBV and showed an increase of lycopene titer as expected. The loss of PHBV caused a decrease in dry cell weight by $42 \%$ (Figure 6). On the other hand, the lycopene production was sharply enhanced by $73 \%$. This indicated that more acetyl-CoA could flux to lycopene synthesis via MVA pathway with the disruption of PHBV synthesis.

High biomass is necessary to achieve a high yield of lycopene. However, the presence of auxotrophies can cause an organism to grow more slowly than the equivalent prototroph (Pronk, 2002). Furthermore, it is not feasible for high-cell density fermentation and practical application because of the requirement of additional uracil. In Y. lipolytica, the alleviation of both leu2 and ura3 auxotrophies gave a 1.9-fold enhancement in lycopene titer (Schwartz et al., 2017). In this work, we complemented the pyrF auxotrophy in strain 50B6I6 $\Delta$ phaEC. The engineered strain 50FB6I6 $\Delta$ phaEC showed no difference in dry cell weight compared with 50B6I6 $\Delta$ phaEC (Figure 6), but gave a little decrease in lycopene titer and production. The low lycopene accumulation after the complementation of pyrF gene might be ascribed to the fact that the utilization efficiency of the uracil synthesized in vivo was lower than that of the uracil added for cell growth. However, no need for uracil overweighed the slight decrease of lycopene production as for developing a cost-effective industrial strain.

This work reveals that $H$. mediterranei possesses a great potential for lycopene biosynthesis and much more efforts are needed to further increase its lycopene production. The reduction of FPP flux to the squalene biosynthetic pathway (a competing pathway for carotenoid synthesis) is expected to further increase lycopene yield. This strategy has been used to improve lycopene production in yeast (Xie et al., 2015b). Besides, modulation of the NADPH and ATP levels is another alternative approach for further enhancing lycopene synthesis in $H$. mediterranei. Additionally, optimization of culture conditions and fed-batch fermentation might also be adopted for maximizing lycopene production in $H$. mediterranei.

\section{CONCLUSION}

In this work, we engineered a haloarchaeon, $H$. mediterranei, as a novel host for lycopene overproduction by adopting multiple strategies. Introducing a constitutive promoter enhanced the expression level of the rate-limiting enzyme encoding gene, $\operatorname{crt} B$, and disrupting the bacterioruberin synthesis significantly increased the lycopene production and purity. Importing different heterologous crt expression cassettes were also an effective method for improving lycopene production. Further blocking PHBV synthesis to direct more acetyl-CoA flux into carotenoid synthesis showed a dramatic increase in lycopene production, up to $119.25 \pm 0.55 \mathrm{mg} / \mathrm{g} \mathrm{DCW}$, in shake flask fermentation. Complementation of $p y r F$ in the engineered strain $50 \mathrm{~B} 6 \mathrm{I} 6 \Delta$ phaEC had no increase in both dry cell weight and lycopene production, but it could grow without addition of uracil and thus is more suitable for industrial application. The engineering pathway that we developed in this study shows the potential for high-level production of lycopene and offers biological insights into carotenoid production in haloarchaea.

\section{AUTHOR CONTRIBUTIONS}

Z-QZ, JH, and HX conceived the project, analyzed the data, and drafted the manuscript. Z-QZ and JZ performed the study. QX, $\mathrm{D}-\mathrm{HZ}$, and $\mathrm{JH}$ critically revised the manuscript. All authors read and approved the final manuscript.

\section{FUNDING}

This work was financially supported by the National Natural Science Foundation of China (Grant Nos. NSFC-31330001 and NSFC-91751201), National Science and Technology Foundation Project of China (Grant No. 2015FY110100), and the Youth Innovation Promotion Association of CAS (Grant No. 2015070).

\section{ACKNOWLEDGMENTS}

We thank Yeh-Hsing Lao at Columbia University, Sumit Kumar at Indian Institute of Technology and Ruchira Mitra for assistance in manuscript writing and Tong Sun for his technical support.

\section{SUPPLEMENTARY MATERIAL}

The Supplementary Material for this article can be found online at: https://www.frontiersin.org/articles/10.3389/fmicb.2018. 02893/full\#supplementary-material 


\section{REFERENCES}

Alper, H., Jin, Y.-S., Moxley, J. F., and Stephanopoulos, G. (2005). Identifying gene targets for the metabolic engineering of lycopene biosynthesis in Escherichia coli. Metab. Eng. 7, 155-164. doi: 10.1016/j.ymben.2004.12.003

Alper, H., and Stephanopoulos, G. (2008). Uncovering the gene knockout landscape for improved lycopene production in E. coli. Appl. Microbiol. Biotechnol. 78, 801-810. doi: 10.1007/s00253-008-1373-x

Altschul, S. F., Gish, W., Miller, W., Myers, E. W., and Lipman, D. J. (1990). Basic local alignment search tool. J. Mol. Biol. 215, 403-410. doi: 10.1006/jmbi.1990. 9999

Anthony, J. R., Anthony, L. C., Nowroozi, F., Kwon, G., Newman, J. D., and Keasling, J. D. (2009). Optimization of the mevalonate-based isoprenoid biosynthetic pathway in Escherichia coli for production of the anti-malarial drug precursor amorpha-4,11-diene. Metab. Eng. 11, 13-19. doi: 10.1016/j.ymben. 2008.07.007

Antón, J., Meseguer, I., and Rodríguezvalera, F. (1988). Production of an extracellular polysaccharide by Haloferax mediterranei. Appl. Environ. Microbiol. 54, 2381-2386.

Azami, Y., Hattori, A., Nishimura, H., Kawaide, H., Yoshimura, T., and Hemmi, H. (2014). (R)-mevalonate 3-phosphate is an intermediate of the mevalonate pathway in Thermoplasma acidophilum. J. Biol. Chem. 289, 15957-15967. doi: $10.1074 /$ jbc.M114.562686

Berthelot, K., Estevez, Y., Deffieux, A., and Peruch, F. (2012). Isopentenyl diphosphate isomerase: a checkpoint to isoprenoid biosynthesis. Biochimie 94, 1621-1634. doi: 10.1016/j.biochi.2012.03.021

Bhattacharyya, A., Saha, J., Haldar, S., Bhowmic, A., Mukhopadhyay, U. K., and Mukherjee, J. (2014). Production of poly-3-(hydroxybutyrate-cohydroxyvalerate) by Haloferax mediterranei using rice-based ethanol stillage with simultaneous recovery and re-use of medium salts. Extremophiles 18, 463-470. doi: 10.1007/s00792-013-0622-9

Bischoff, K. M., and Rodwell, V. W. (1996). 3-Hydroxy-3-methylglutarylcoenzyme a reductase from Haloferax volcanii: purification, characterization, and expression in Escherichia coli. J. Bacteriol. 178, 19-23. doi: 10.1128/jb.178. $1.19-23.1996$

Cai, S., Cai, L., Liu, H., Liu, X., Han, J., Zhou, J., et al. (2012). Identification of the haloarchaeal phasin (PhaP) that functions in polyhydroxyalkanoate accumulation and granule formation in Haloferax mediterranei. Appl. Environ. Microbiol. 78, 1946-1952. doi: 10.1128/AEM.07114-11

Cai, S. F., Cai, L., Zhao, D. H., Liu, G. M., Han, J., Zhou, J., et al. (2015). A novel DNA-binding protein, PhaR, plays a central role in the regulation of polyhydroxyalkanoate accumulation and granule formation in the haloarchaeon Haloferax mediterranei. Appl. Environ. Microbiol. 81, 373-385. doi: 10.1128/aem.02878-14

Chamovitz, D., Misawa, N., Sandmann, G., and Hirschberg, J. (1992). Molecular cloning and expression in Escherichia coli of a cyanobacterial gene coding for phytoene synthase, a carotenoid biosynthesis enzyme. FEBS Lett. 296, 305-310. doi: 10.1016/0014-5793(92)80310-D

Chen, C. W., Hsu, S. H., Lin, M. T., and Hsu, Y. H. (2015). Mass production of C-50 carotenoids by Haloferax mediterranei in using extruded rice bran and starch under optimal conductivity of brined medium. Bioprocess. Biosyst. Eng. 38, 2361-2367. doi: 10.1007/s00449-015-1471-y

Chen, Y., Xiao, W. H., Wang, Y., Liu, H., Li, X., and Yuan, Y. J. (2016). Lycopene overproduction in Saccharomyces cerevisiae through combining pathway engineering with host engineering. Microb. Cell Fact. 15:113. doi: 10.1186/s12934-016-0509-4

Chen, Y. Y., Shen, H. J., Cui, Y. Y., Chen, S. G., Weng, Z. M., Zhao, M., et al. (2013). Chromosomal evolution of Escherichia coli for the efficient production of lycopene. BMC Biotechnol. 13:6. doi: 10.1186/1472-6750-13-6

Cline, S. W., Lam, W. L., Charlebois, R. L., Schalkwyk, L. C., and Doolittle, W. F. (1989). Transformation methods for halophilic archaebacteria. Can. J. Microbiol. 35, 148-152. doi: 10.1139/m89-022

Coussement, P., Bauwens, D., Maertens, J., and De Mey, M. (2017). Direct combinatorial pathway optimization. ACS Synth. Biol. 6, 224-232. doi: 10.1021/ acssynbio.6b00122

de Lourdes Moreno, M., Sanchez-Porro, C., Garcia, M. T., and Mellado, E. (2012). Carotenoids' production from halophilic bacteria. Methods Mol. Biol. 892, 207-217. doi: 10.1007/978-1-61779-879-5-12
Don, T. M., Chen, C. W., and Chan, T. H. (2006). Preparation and characterization of poly(hydroxyalkanoate) from the fermentation of Haloferax mediterranei. Sci. Polym. Ed. 17, 1425-1438. doi: 10.1163/156856206778937208

Enfissi, E. M. A., Fraser, P. D., Lois, L.-M., Boronat, A., Schuch, W., and Bramley, P. M. (2005). Metabolic engineering of the mevalonate and nonmevalonate isopentenyl diphosphate-forming pathways for the production of health-promoting isoprenoids in tomato. Plant Biotechnol. J. 3, 17-27. doi: 10.1111/j.1467-7652.2004.00091.x

Fang, C. J., Ku, K. L., Lee, M. H., and Su, N. W. (2010). Influence of nutritive factors on C-50 carotenoids production by Haloferax mediterranei ATCC 33500 with two-stage cultivation. Bioresour. Technol. 101, 6487-6493. doi: 10.1016/j. biortech.2010.03.044

Fraser, P. D., Misawa, N., Linden, H., Yamano, S., Kobayashi, K., and Sandmann, G. (1992). Expression in Escherichia coli, purification, and reactivation of the recombinant Erwinia uredovora phytoene desaturase. J. Biol. Chem. 267, 1989119895.

Fraser, P. D., Romer, S., Shipton, C. A., Mills, P. B., Kiano, J. W., Misawa, N., et al. (2002). Evaluation of transgenic tomato plants expressing an additional phytoene synthase in a fruit-specific manner. Proc. Natl. Acad. Sci. U.S.A. 99, 1092-1097. doi: 10.1073/pnas.241374598

Gajowik, A., and Dobrzynska, M. M. (2014). Lycopene - antioxidant with radioprotective and anticancer properties. A review. Rocz. Panstw. Zakl. Hig. $65,263-271$.

Giliberto, L., Perrotta, G., Pallara, P., Weller, J. L., Fraser, P. D., Bramley, P. M., et al. (2005). Manipulation of the blue light photoreceptor cryptochrome 2 in tomato affects vegetative development, flowering time, and fruit antioxidant content. Plant Physiol. 137, 199-208. doi: 10.1104/pp.104.051987

Goldstein, J. L., and Brown, M. S. (1990). Regulation of the mevalonate pathway. Nature 343, 425-430. doi: 10.1038/343425a0

Guo, J., Wang, S., Yu, X., Dong, R., Li, Y., Mei, X., et al. (2018). Polyamines regulate strawberry fruit ripening by abscisic acid, auxin, and ethylene. Plant Physiol. 177, 339-351. doi: 10.1104/pp.18.00245

Han, J., Hou, J., Zhang, F., Ai, G., Li, M., Cai, S., et al. (2013). Multiple propionyl coenzyme A-supplying pathways for production of the bioplastic poly(3hydroxybutyrate-co-3-hydroxyvalerate) in Haloferax mediterranei. Appl. Environ. Microbiol. 79, 2922-2931. doi: 10.1128/aem.03915-12

Han, J., Lu, Q., Zhou, L., Zhou, J., and Xiang, H. (2007). Molecular characterization of the phaEC $(\mathrm{Hm})$ genes, required for biosynthesis of poly(3-hydroxybutyrate) in the extremely halophilic archaeon Haloarcula marismortui. Appl. Environ. Microbiol. 73, 6058-6065. doi: 10.1128/AEM.00953-07

Han, J., Wu, L. P., Liu, X. B., Hou, J., Zhao, L. L., Chen, J. Y., et al. (2017). Biodegradation and biocompatibility of haloarchaea-produced poly(3hydroxybutyrate-co-3-hydroxyvalerate) copolymers. Biomaterials 139, 172186. doi: $10.1016 /$ j.biomaterials.2017.06.006

Han, J., Zhang, F., Hou, J., Liu, X., Li, M., Liu, H., et al. (2012). Complete genome sequence of the metabolically versatile halophilic archaeon Haloferax mediterranei, a poly(3-hydroxybutyrate-co-3-hydroxyvalerate) producer. J. Bacteriol. 194, 4463-4464. doi: 10.1128/JB.00880-12

Hemmi, H., Ohnuma, S., Nagaoka, K., and Nishino, T. (1998). Identification of genes affecting lycopene formation in Escherichia coli transformed with carotenoid biosynthetic genes: candidates for early genes in isoprenoid biosynthesis. J. Biochem. 123, 1088-1096. doi: 10.1093/oxfordjournals.jbchem. a022047

Hosfield, D. J., Zhang, Y., Dougan, D. R., Broun, A., Tari, L. W., Swanson, R. V., et al. (2004). Structural basis for bisphosphonate-mediated inhibition of isoprenoid biosynthesis. J. Biol. Chem. 279, 8526-8529. doi: 10.1074/jbc. C300511200

Kang, M. J., Lee, Y. M., Yoon, S. H., Kim, J. H., Ock, S. W., Jung, K. H., et al. (2005). Identification of genes affecting lycopene accumulation in Escherichia coli using a shot-gun method. Biotechnol. Bioeng. 91, 636-642. doi: 10.1002/bit. 20539

Kolotilin, I. (2008). Assessment of Transgenic Approaches to Increase Lycopene Content in Ripe Tomato Fruits. Ph.D. thesis. Hebrew University, Jerusalem.

Kolotilin, I., Koltai, H., Bar-Or, C., Chen, L., Nahon, S., Shlomo, H., et al. (2011). Expressing yeast $S A M d c$ gene confers broad changes in gene expression and alters fatty acid composition in tomato fruit. Physiol. Plant 142, 211-223. doi: 10.1111/j.1399-3054.2011.01458.x 
Krogh, A., Larsson, B., von Heijne, G., and Sonnhammer, E. L. L. (2001). Predicting transmembrane protein topology with a hidden Markov model: application to complete genomes. J. Mol. Biol. 305, 567-580. doi: 10.1006/jmbi.2000.4315

Leonard, E., Ajikumar, P. K., Thayer, K., Xiao, W.-H., Mo, J. D., Tidor, B., et al. (2010). Combining metabolic and protein engineering of a terpenoid biosynthetic pathway for overproduction and selectivity control. Proc. Natl. Acad. Sci. U.S.A. 107, 13654-13659. doi: 10.1073/pnas.1006138107

Liu, H. L., Han, J., Liu, X. Q., Zhou, J., and Xiang, H. (2011). Development of pyrF-based gene knockout systems for genome-wide manipulation of the archaea Haloferax mediterranei and Haloarcula hispanica. J. Genet. Genomics 38, 261-269. doi: 10.1016/j.jgg.2011.05.003

Liu, X.-J., Liu, R.-S., Li, H.-M., and Tang, Y.-J. (2012). Lycopene production from synthetic medium by Blakeslea trispora NRRL $2895(+)$ and $2896(-)$ in a stirred-tank fermenter. Bioprocess. Biosyst. Eng. 35, 739-749. doi: 10.1007/ s00449-011-0654-4

Lombard, J., and Moreira, D. (2011). Origins and early evolution of the mevalonate pathway of isoprenoid biosynthesis in the three domains of life. Mol. Biol. Evol. 28, 87-99. doi: 10.1093/molbev/msq177

Lu, Q., Han, J., Zhou, L., Coker, J. A., DasSarma, P., DasSarma, S., et al. (2008a). Dissection of the regulatory mechanism of a heat-shock responsive promoter in haloarchaea: a new paradigm for general transcription factor directed archaeal gene regulation. Nucleic Acids Res. 36, 3031-3042. doi: 10.1093/nar/gkn152

Lu, Q., Han, J., Zhou, L., Zhou, J., and Xiang, H. (2008b). Genetic and biochemical characterization of the poly(3-hydroxybutyrate-co-3-hydroxyvalerate) synthase in Haloferax mediterranei. J. Bacteriol. 190, 4173-4180. doi: 10.1128/jb.0013408

Lv, P., Li, N., Liu, H., Gu, H., and Zhao, W.-E. (2015). Changes in carotenoid profiles and in the expression pattern of the genes in carotenoid metabolisms during fruit development and ripening in four watermelon cultivars. Food Chem. 174, 52-59. doi: 10.1016/j.foodchem.2014.11.022

Mattoo, A. K., Chung, S. H., Goyal, R. K., Fatima, T., Solomos, T., Srivastava, A., et al. (2007). Overaccumulation of higher polyamines in ripening transgenic tomato fruit revives metabolic memory, upregulates anabolismrelated genes, and positively impacts nutritional quality. J. AOAC Int. 90, 1456-1464.

Mattoo, A. K., Sobolev, A. P., Neelam, A., Goyal, R. K., Handa, A. K., and Segre, A. L. (2006). Nuclear magnetic resonance spectroscopy-based metabolite profiling of transgenic tomato fruit engineered to accumulate spermidine and spermine reveals enhanced anabolic and nitrogen-carbon interactions. Plant Physiol. 142, 1759-1770. doi: 10.1104/pp.106.084400

Mehta, R. A., Cassol, T., Li, N., Ali, N., Handa, A. K., and Mattoo, A. K. (2002). Engineered polyamine accumulation in tomato enhances phytonutrient content, juice quality, and vine life. Nat. Biotechnol. 20, 613-618. doi: 10.1038/ nbt0602-613

Namitha, K. K., and Negi, P. S. (2018). Transformation of tomato cv. arka ahuti (Solanum lycopersicum L.) with phytoene desaturase (CrtI) and lycopene $\beta$-cyclase (CrtY) genes increases carotenoid content and antioxidant potential. J. Plant Biochem. Biotechnol. 27, 68-77. doi: 10.1007/s13562-017-0417-7

Naziri, D., Hamidi, M., Hassanzadeh, S., Tarhriz, V., Maleki Zanjani, B., Nazemyieh, H., et al. (2014). Analysis of carotenoid production by Halorubrum sp. TBZ126; an extremely halophilic archeon from Urmia Lake. Adv. Pharm. Bull. 4, 61-67. doi: 10.5681/apb.2014.010

Neily, M. H., Matsukura, C., Maucourt, M., Bernillon, S., Deborde, C., Moing, A., et al. (2011). Enhanced polyamine accumulation alters carotenoid metabolism at the transcriptional level in tomato fruit over-expressing spermidine synthase. J. Plant Physiol. 168, 242-252. doi: 10.1016/j.jplph.2010.07.003

Oren, A., and Hallsworth, J. E. (2014). Microbial weeds in hypersaline habitats: the enigma of the weed-like Haloferax mediterranei. FEMS Microbiol. Lett. 359, 134-142. doi: 10.1111/1574-6968.12571

Palmer, B. R., and Marinus, M. G. (1994). The dam and $\mathrm{dcm}$ strains of Escherichia coli - a review. Gene 143, 1-12. doi: 10.1016/0378-1119(94)90597-5

Papaioannou, E. H., Liakopoulou-Kyriakides, M., and Karabelas, A. J. (2016). Natural origin lycopene and its "Green" downstream processing. Crit. Rev. Food Sci. Nutr. 56, 686-709. doi: 10.1080/10408398.2013.817381

Peck, R. F., Echavarri-Erasun, C., Johnson, E. A., Ng, W. V., Kennedy, S. P., Hood, L., et al. (2001). Brp and blh are required for synthesis of the retinal cofactor of bacteriorhodopsin in Halobacterium salinarum. J. Biol. Chem. 276, 5739-5744. doi: 10.1074/jbc.M009492200
Peck, R. F., Johnson, E. A., and Krebs, M. P. (2002). Identification of a lycopene beta-cyclase required for bacteriorhodopsin biogenesis in the archaeon Halobacterium salinarum. J. Bacteriol. 184, 2889-2897. doi: 10.1128/jb.184.11. 2889-2897.2002

Peck, R. F., Plesa, A. M., Graham, S. M., Angelini, D. R., and Shaw, E. L. (2017). Opsin-mediated inhibition of bacterioruberin synthesis in halophilic archaea. J. Bacteriol. 199:e00303-17. doi: 10.1128/jb.00303-17

Perkins-Veazie, P., and Davis, A. R. (2004). In search of high lycopene watermelon. Cucurbit Genet. Coop. Rep. 27, 51-53.

Pronk, J. T. (2002). Auxotrophic yeast strains in fundamental and applied research. Appl. Environ. Microbiol. 68, 2095-2100. doi: 10.1128/AEM.68.5.2095-2100. 2002

Ray, B. L., and Raetz, C. R. (1987). The biosynthesis of gram-negative endotoxin. A novel kinase in Escherichia coli membranes that incorporates the $4^{\prime}$ phosphate of lipid A. J. Biol. Chem. 262, 1122-1128.

Rodrigo-Banos, M., Garbayo, I., Vilchez, C., Bonete, M. J., and MartinezEspinosa, R. M. (2015). Carotenoids from haloarchaea and their potential in biotechnology. Mar. Drugs 13, 5508-5532. doi: 10.3390/md13095508

Sambrook, H. C. (1989). Molecular Cloning : A Laboratory Manual. Cold Spring Harbor, NY: Cold Spring Harbor Laboratory.

Schwartz, C., Frogue, K., Misa, J., and Wheeldon, I. (2017). Host and pathway engineering for enhanced lycopene biosynthesis in Yarrowia lipolytica. Front. Microbiol. 8:11. doi: 10.3389/fmicb.2017.02233

Sies, H., and Stahl, W. (1998). Lycopene: antioxidant and biological effects and its bioavailability in the human. Proc. Soc. Exp. Biol. Med. 218, 121-124. doi: 10.3181/00379727-218-44285a

Simkin, A. J., Gaffé, J., Alcaraz, J.-P., Carde, J.-P., Bramley, P. M., Fraser, P. D., et al. (2007). Fibrillin influence on plastid ultrastructure and pigment content in tomato fruit. Phytochemistry 68, 1545-1556. doi: 10.1016/j.phytochem.2007. 03.014

Singh, A., and Singh, A. K. (2017). Haloarchaea: worth exploring for their biotechnological potential. Biotechnol. Lett. 39, 1793-1800. doi: 10.1007/ s10529-017-2434-y

Steussy, C. N., Vartia, A. A., Burgner, J. W. II, Sutherlin, A., Rodwell, V. W., and Stauffacher, C. V. (2005). X-ray crystal structures of HMG-CoA synthase from Enterococcus faecalis and a complex with its second substrate/inhibitor acetoacetyl-CoA. Biochemistry 44, 14256-14267. doi: 10.1021/bi051487x

Strand, A., Shivaji, S., and Liaaen-Jensen, S. (1997). Bacterial carotenoids 55. C50carotenoids $25 . \dagger$ revised structures of carotenoids associated with membranes in psychrotrophic Micrococcus roseus. Biochem. Syst. Ecol. 25, 547-552. doi: 10.1016/S0305-1978(97)00039-2

Su, A., Chi, S., Li, Y., Tan, S., Qiang, S., Chen, Z., et al. (2018). Metabolic redesign of Rhodobacter sphaeroides for lycopene production. J. Agric. Food Chem. 66, 5879-5885. doi: 10.1021/acs.jafc.8b00855

Tao, S., Miao, L., Li, Q., Dai, G., Lu, F., Tao, L., et al. (2014). Production of lycopene by metabolically-engineered Escherichia coli. Biotechnol. Lett. 36, 1515-1522. doi: 10.1007/s10529-014-1543-0

VanNice, J. C., Skaff, D. A., Keightley, A., Addo, J. K., Wyckoff, G. J., and Miziorko, H. M. (2014). Identification in Haloferax volcanii of phosphomevalonate decarboxylase and isopentenyl phosphate kinase as catalysts of the terminal enzyme reactions in an archaeal alternate mevalonate pathway. J. Bacteriol. 196, 1055-1063. doi: 10.1128/jb.01230-13

VanNice, J. C., Skaff, D. A., Wyckoff, G. J., and Miziorko, H. M. (2013). Expression in Haloferax volcanii of 3-hydroxy-3-methylglutaryl coenzyme A synthase facilitates isolation and characterization of the active form of a key enzyme required for polyisoprenoid cell membrane biosynthesis in halophilic archaea. J. Bacteriol. 195, 3854-3862. doi: 10.1128/jb.00485-13

Viuda-Martos, M., Sanchez-Zapata, E., Sayas-Barbera, E., Sendra, E., PerezAlvarez, J. A., and Fernandez-Lopez, J. (2014). Tomato and tomato byproducts. Human health benefits of lycopene and its application to meat products: a review. Crit. Rev. Food Sci. Nutr. 54, 1032-1049. doi: 10.1080/10408398.2011. 623799

Wang, Y., Chen, X., Hong, X., Du, S., Liu, C., Gong, W., et al. (2016). Cyclase inhibitor tripropylamine significantly enhanced lycopene accumulation in Blakeslea trispora. J. Biosci. Bioeng. 122, 570-576. doi: 10.1016/j.jbiosc.2016.05. 001

Wang, Y. L., Pang, J., Zheng, Y. M., Jiang, P. P., Gong, W. F., Chen, X. W., et al. (2017). Genetic manipulation of the bifunctional gene, carRA, to enhance 
lycopene content in Blakeslea trispora. Biochem. Eng. J. 119, 27-33. doi: 10.1016/ j.bej.2016.12.011

Wei, Y., Mohsin, A., Hong, Q., Guo, M., and Fang, H. (2017). Enhanced production of biosynthesized lycopene via heterogenous MVA pathway based on chromosomal multiple position integration strategy plus plasmid systems in Escherichia coli. Bioresour. Technol. 250, 382-389. doi: 10.1016/j.biortech.2017. 11.035

Wimalasiri, D., Brkljaca, R., Piva, T. J., Urban, S., and Huynh, T. (2017). Comparative analysis of carotenoid content in Momordica cochinchinensis (Cucurbitaceae) collected from Australia, Thailand and Vietnam. J. Food Sci. Technol. 54, 2814-2824. doi: 10.1007/s13197-017-2719-0

Wu, T., Ye, L., Zhao, D., Li, S., Li, Q., Zhang, B., et al. (2018). Engineering membrane morphology and manipulating synthesis for increased lycopene accumulation in Escherichia coli cell factories. 3 Biotech 8:269. doi: 10.1007/ s13205-018-1298-8

Xie, W., Lv, X., Ye, L., Zhou, P., and Yu, H. (2015a). Construction of lycopeneoverproducing Saccharomyces cerevisiae by combining directed evolution and metabolic engineering. Metab. Eng. 30, 69-78. doi: 10.1016/j.ymben.2015.04. 009

Xie, W., Ye, L., Lv, X., Xu, H., and Yu, H. (2015b). Sequential control of biosynthetic pathways for balanced utilization of metabolic intermediates in Saccharomyces cerevisiae. Metab. Eng. 28, 8-18. doi: 10.1016/j.ymben.2014.11.007

$\mathrm{Xu}$, J., Xu, X., Xu, Q., Zhang, Z., Jiang, L., and Huang, H. (2018). Efficient production of lycopene by engineered $E$. coli strains harboring different types of plasmids. Bioprocess. Biosyst. Eng. 41, 489-499. doi: 10.1007/s00449-0171883-y

Xue, Q., Liu, X. B., Lao, Y. H., Wu, L. P., Wang, D., Zuo, Z. Q., et al. (2018). Antiinfective biomaterials with surface-decorated tachyplesin I. Biomaterials 178, 351-362. doi: 10.1016/j.biomaterials.2018.05.008

Zhao, D., Cai, L., Wu, J., Li, M., Liu, H., Han, J., et al. (2013). Improving polyhydroxyalkanoate production by knocking out the genes involved in exopolysaccharide biosynthesis in Haloferax mediterranei. Appl. Microbiol. Biotechnol. 97, 3027-3036. doi: 10.1007/s00253-012-4415-3

Zhu, F., Lu, L., Fu, S., Zhong, X., Hu, M., Deng, Z., et al. (2015). Targeted engineering and scale up of lycopene overproduction in Escherichia coli. Process Biochem. 50, 341-346. doi: 10.1016/j.procbio.2014.12.008

Conflict of Interest Statement: The authors declare that the research was conducted in the absence of any commercial or financial relationships that could be construed as a potential conflict of interest.

Copyright (c) 2018 Zuo, Xue, Zhou, Zhao, Han and Xiang. This is an open-access article distributed under the terms of the Creative Commons Attribution License (CC BY). The use, distribution or reproduction in other forums is permitted, provided the original author(s) and the copyright owner(s) are credited and that the original publication in this journal is cited, in accordance with accepted academic practice. No use, distribution or reproduction is permitted which does not comply with these terms. 